\title{
Effect of low magnetic field treatment on spectra of radiative recombination centers in indium phosphide structures
}

\author{
R. Red'ko \\ V. Lashkaryov Institute of Semiconductor Physics, NAS of Ukraine \\ 45, prospect Nauky, 03028 Kyiv, Ukraine \\ Phone: 38 (044) 525-94-64; e-mail:re_rom@ukr.net
}

\begin{abstract}
We present the results of investigations of the effect caused by low magnetic field treatment on InP single crystals impurity-defect composition. This effect was found when studying the radiative recombination (luminescence) spectra in the $0.6-2.5 \mu \mathrm{m}$ range at $77 \mathrm{~K}$. The static magnet with $B=0.44 \mathrm{~T}$ was used as a source of magnetic field. We studied samples of two groups: porous InP crystals and epitaxial layers grown on porous substrate. The crystals of both groups were not specially doped. It has been obtained that treatment even for $0.02 \mathrm{~min}$ resulted in considerable changes in luminescence spectra. The luminescence intensities after treatment increase at first, but later behavior is nonmonotonic: next treatment can result in decrease or increase a value of intensities of both observed bands. It should be noted that the luminescence intensities of epitaxial layers, perhaps, changed as well as concentration of nonradiative centers changed. But for porous indium phosphide, these features were not observed.
\end{abstract}

Keywords: luminescence, low magnetic field, epitaxial layers.

Manuscript received 03.11.08; accepted for publication 18.12.08; published online 02.03.09.

\section{Introduction}

The structures based on III-V semiconductor substrate material is widely used in modern micro- and photoelectronic devices. Processes of modificating the semiconductor impurity-defect states caused by thermal, radiation and other traditional action factors are defined as well as it was possible. Noted kinds of treatment give results that are in good agreement with a theory. But transformations of semiconductor microstructure can occur without temperature enhancing and receiving a large value of energy. Such modification of defect structure is possible due to using the microwave or low magnetic field treatments. The latter is more perspective and cost effective in some cases. At the same time, the question of interaction mechanisms for semiconductor material with microwave radiation and low magnetic field are open till now. There are some experimental results testifying about similar modification processes for these both kinds of treatment $[1,2]$.

In this work, the results of studying the low magnetic field (LMF) effects on spectra of local states in porous indium phosphide and InP epitaxial layers, to be compared with each other and with results of super-high frequency (SHF) treatments, has been investigated and discussed.

\section{Experimental}

Porous and epitaxial layers of indium phosphide of $n$ type prepared in accord to the technique described in [3], with the surface orientation (100) and concentration of carriers $10^{17} \mathrm{~cm}^{-3}$, were the object of our researches. The samples were treated in LMF of static magnet with $B=0.44 \mathrm{~T}$. The intensity of the LMF treatment was varied by changing the exposure in magnetic direction for porous ( $t_{\text {treat }}^{\text {por }}=0.02,1,2,5,8,18 \mathrm{~min}$ ) and epitaxial ( $t_{\text {treat }}^{\text {epi }}=1,2,3,5,10 \mathrm{~min}$ ) layers.

The photoluminescence (PL) measurements were carried out at $77 \mathrm{~K}$ within the spectral range of 0.6$2.5 \mu \mathrm{m}$. Excitation of PL was realized using the light of powerful incandescent lamp ПЖ-100 with $\lambda_{\text {ex }} \leq 600 \mathrm{~nm}$.

\section{Results and discussion}

PL spectra of our samples in their initial state consist of only two bands - at 1.14, $1.41 \mathrm{eV}$ and $1.02,1.22 \mathrm{eV}$ for InP epilayers and porous material, respectively. 
Literature data have no definite interpretation of the nature of $1.41 \mathrm{eV}$ band in InP. In some works, this band is related with uncontrolled presence of Si impurity [4], in the others - with band-to-band recombination of nonequilibrium carriers. On the other hand, this band is related with a shallow donor [5]. The band in the region of $1.14 \mathrm{eV}$ is caused by $\left[\mathrm{Fe}_{\mathrm{In}}+\mathrm{V}_{\mathrm{P}}\right]$ complexes [4]. According to $[6,7]$, we should believe that the bands near 1.02 and $1.22 \mathrm{eV}$ are related with various complexes with participation of the vacancies: $\left[\mathrm{V}_{\mathrm{P}}+\right.$ impurity $]$ and $\left[\mathrm{V}_{\mathrm{In}}+\right.$ impurity $]$ respectively. Probably, due to presence of chemical reaction products in pore direction, the frequency position of the latter band is little shifted to the red region of wavelengths comparing with that obtained in [8]. The LMF treatment resulted in decrease of intensities of all the observed bands. But later treatment showed different behavior of PL peaks: for epilayers (Table 1) the factor of intensity decrease was similar for its own bands during the experiment, but porous material had no resemblence (Table 2). For this material, the value of intensity never backed to initial position. So, one can note that this behavior of intensities for the first group of the samples is probably related with generation/annihilation of nonradiative centers, which are $\mathrm{Fe}$ atoms in InP [5]. Obviously, reduction of $\left[\mathrm{Fe}_{\mathrm{In}}+\mathrm{V}_{\mathrm{P}}\right]$ copmlexes confirms it.

Table 1. Values of intensity relations $\left(\frac{I_{i}}{I_{0}}\right)$ for InP epilayers.

\begin{tabular}{|c|c|c|c|c|c|c|}
\hline $\begin{array}{l}\text { Time of low } \\
\text { Frequency } \\
\text { position of } \mathrm{PL} \text { band } \\
\text { treatment, }\end{array}$ & $I_{0}$ & 1 & 2 & 3 & 5 & 10 \\
\hline $1.41 \mathrm{eV}$ & 52 & 0.94 & 2.52 & 3.02 & 1.83 & 3.87 \\
\hline $1.14 \mathrm{eV}$ & 68 & 0.91 & 2.27 & 2.71 & 1.82 & 3.44 \\
\hline
\end{tabular}

Table 2. Values of intensity relations $\left(\frac{I_{i}}{I_{0}}\right)$ for porous InP.

\begin{tabular}{|c|c|c|c|c|c|c|c|}
\hline $\begin{array}{r}\text { Time of low } \\
\text { magnetic } \\
\text { field } \\
\text { treatment, } \\
\text { min }\end{array}$ & $I_{0}$ & 0.02 & 1 & 2 & 5 & 8 & 18 \\
$\begin{array}{l}\text { Frequency } \\
\text { position } \\
\text { of PL band }\end{array}$
\end{tabular}

The rise of intensities for both bands after LMF treatment indicates to possible increase in the concentration of $\mathrm{V}_{\mathrm{P}}$ that are the components of $1.14 \mathrm{eV}$ band centers and can take part in formation of a shallow donor level at $1.41 \mathrm{eV}$. So far as the isolated $\mathrm{V}_{\mathrm{P}}$ acceptors have a higher cross section for nonequilibrium hole capture than DA complexes [9], the rise of $V_{P}$ concentration should be more effective for the band $1.41 \mathrm{eV}$ intensity. That is observed in the experiment.

Observed transformation of PL spectrum during LMF treatment occurs at low energy absorption: $\mu_{\mathrm{B}} B \sim 10^{-5} \mathrm{eV}$, which is considerably smaller than the $k T$ value at room temperature. So, it is necessary to involve an alternative mechanism for explaining results of the experiment. The intensity changes of PL peaks in our samples occur after treatment by low but non-zero field, which is presumably caused by the strong interaction with electron spins in some atom, so that a finite field is required to obtain a new metastable state. This can result in the destruction of the complex formed by this atom $\left(\left[\mathrm{Fe}_{\mathrm{In}}+\mathrm{V}_{\mathrm{P}}\right]\right.$ for example). The non-radiative centers $(\mathrm{Fe})$ and $V_{P}$ appear in this case. An atom can leave this state and go to initial one after the next treatment. This explains the nonmonotonic and synchronous change of the intensities inherent to 1.41 and $1.14 \mathrm{eV}$ bands. Similar nonmonotonic processes were observed in [10, 11] during SHF treatment of III-V semiconductors. Because of reaction between the same defect complexes, the same absorbed energy value $(<k T)$ and similar behavior of intensity dependences we can draw a possible conclusion about the same mechanisms of interaction for low energy treatments (LMF and SHF) and researched semiconductor.

\section{Conclusions}

Thus, the effect of LMF-treatment on the defect structure of subsurface layers and on processes of rebuilding the centres of radiative and nonradiative recombination in InP has been obtained. There are different ways for intensity dependences of porous indium phosphide and InP epilayers, caused probably by different initial impurity-defect composition of researched materials. Observed transformation reminds spectral dependences for microwave radiation interaction with III-V semiconductor compounds. To ascertain the micromechanisms of LMF interaction with semiconductor compounds and structures based on them, the further experiments are needed, which are in progress.

\section{Acknowledgments}

The author is grateful to Drs. I.N. Arsentyev and V.P. Ulin for the provision of samples and to Dr. V.V. Milenin for his permanent interest to the work and the fruitful discussions. 


\section{References}

1. R.V. Konakova, V.V. Milenin, R.A. Red'ko, S.M. Red'ko, Features of phosphide indium radiative recombination at microwave and magnetic field treatments // Fizika $i$ khimiya tverdogo tila 9, No 2, p. 379-383 (2008) (in Ukrainian).

2. I.N. Arsentyev, R.V. Konakova, V.V. Milenin, R.A. Red'ko, I.S. Tarasov, Features of radiative recombination of porous and epitaxial layers InP at magnetic field and microwave treatment // Proc. of the $3^{\text {rd }}$ Ukrainian Science Conference of Semiconductor Physics, Odesa, 2007, p. 72 (in Ukrainian).

3. I.N. Arsentyev, A.B. Bobyl, S.G. Konnikov, I.S. Tarasov, V.P. Ulin, M.V. Shishkov, N.S. Boltovets, V.N. Ivanov, A.E. Belyaev, R.V. Konakova, Ya.Ya. Kudryk, A.B. Kamalov, P.M. Lytvyn, E.P. Markovskiy, V.V. Milenin, R.A. Red'ko, Porous nanostructured InP: technology, properties, application // Semiconductor Physics, Quantum Electronics and Optoelectronics 8, No 4, p. 95-104 (2005).

4. V.I. Gavrilenko, A.M. Grehov, D.V. Korbutjak and V.G. Litovchenko, Optical Properties of Semiconductors. Naukova dumka, Kiev, 1987, p. 353-369, 379-385 (in Russian).

5. S. Doğan, S. Tüzemen, Direct recognition of nonradiative recombination centers in semi-insulating LEC InP:Fe using double excitation photoluminescence // J. Luminescence 128, p. 232238 (2008).
6. A.B. Georgobiani, A.V. Mikulyonok, I.G. Stoyanova et. al., Non-equilibrium carrier radiative recombination in indium phosphide single crystals // Phys. status solidi (a) 80, No 1, p. 109-115 (1983).

7. H. Temkin, B.V. Dutt, W.A. Bonner et al., Deep radiative levels in InP // J. Appl. Phys. 53, No 11, p. 7526-7533 (1982).

8. E.P. Domashevskaya, V.A. Terekhov, V.M. Fashkarov, S.Yu. Turishchev, S.L. Molodtsov, D.V. Vyalikh, D.A. Vinokurov, V.P. Ulin, S.G. Konnikov, M.V. Shishkov, I.N. Arsentyev, I.S. Tarasov, Zh.I. Alferov, Synchrotron investigation of electron-energy spectra in $\mathrm{A}^{\mathrm{III}} \mathrm{B}^{\mathrm{V}}$ nanostructures // Fizika Tekhnika Poluprovodnikov 37, p. 10171022 (in Russian).

9. M.K. Sheikman, I.B. Ermolovich and G.L. Belenkii, Mechanisms of orange, red and infrared photoluminescences in CdS single crystals and parameters of emission centres // Fizika Tverdogo Tela 10, p. 2628-2638 (1968) (in Russian).

10. R. Red'ko, S. Red'ko, Effect of the microwave radiation treatment of porous indium phosphide on spectra of radiative recombination centers // Semiconductor Physics, Quantum Electronics and Optoelectronics 10, No 3, p. 75-76 (2007).

11. I.B. Ermolovich, G.V. Milenin, V.V. Milenin, R.V. Konakova and R.A. Red'ko, Modification of the defect structure in binary semiconductors under the action of microwave radiation // Technical Physics 52, No 9, p. 1173-1177 (2007). 